\title{
Comparative efficacy and safety of $\beta$-lactam/ $\beta$-lactamase inhibitors versus cabapenems for febrile neutropenia empiric therapy: A systematic review and meta analysis
}

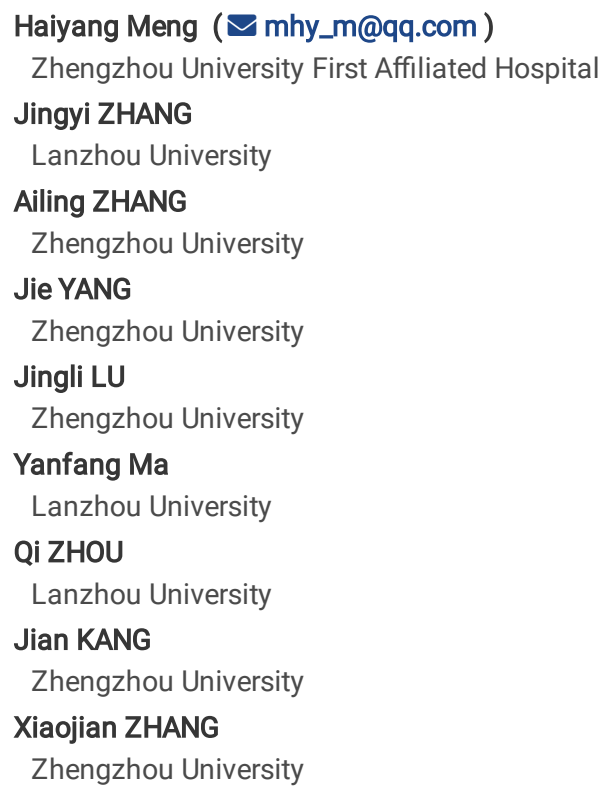

Research

Keywords: PubMed, Embase, Cochrane library databases, Web of Science

Posted Date: August 31st, 2020

DOl: https://doi.org/10.21203/rs.3.rs-62389/v1

License: (9) (1) This work is licensed under a Creative Commons Attribution 4.0 International License. Read Full License 


\section{Abstract \\ Background}

The efficacy and safety of $\beta$-lactam/ $\beta$-lactamase inhibitors (BL/BLIs) versus carbapenems for febrile neutropenia empiric therapy are controversial.

\section{Methods}

PubMed, Embase, Cochrane library databases, Web of Science and Google scholar were searched up to 1 April 2020. Studies were included if they compared BL/BLIs versus carbapenem for febrile neutropenia patients undergoing chemotherapy for either solid tumours or haematological malignancies among adults and children. We pooled the treatment success rate, mortality and adverse events.

\section{Results}

Nine RCTs were included. There was no differences between carbapenems and BL/BLIs were observed in terms of treatment success without modification (RR 1.04, 95\% Cl 0.93-1.15), no differences were observed in the subgroups of BL/BLIs, adults and children. No significant differences were found in all-cause mortality (RR 1.15,95\% $\mathrm{Cl}$ 0.64-2.06). Our study shows that gastrointestinal events are the most common adverse effects, nausea/vomiting were significantly more common with carbapenems (RR $2.83,95 \% \mathrm{Cl} 1.35-5.92, P=0.006$ ), however, diarrhea were more common with BL/BLIs (RR 0.47, 95\% Cl 0.27-0.80, $P=0.006$ ).

\section{Conclusions}

The efficacy and safety of BL/BLIs with carbapenems were comparable in empiric treatment of febrile neutropenia.

\section{Introduction}

Despite improvements in cancer managerment, febrile neutropenia (FN) remains a serious complication of cancer chemotherapy, with significant morbidity, mortality and healthcare resource use[1]. Broad spectrum $\beta$-lactams such as imipenem/cilastatin, meropenem, piperacillin/tazobactam and amoxicillin/clavulanate are recommended for patients with febrile neutropenia by guidelines[2, 3]. In addition, other b-lactam/b-lactamase inhibitors (BL/BLIs) such as cefoperazone/sulbactam and ceftolozane/tazobactam have also been investigated in febrile neutropenia patients[4, 5]. However, despite many trials had been conducted, no clear conclusions to be drawn which empirical therapeutic regimen for febrile neutropenia empiric therapy is better than others[3]. In recent years, the increasing proportion of multidrug-resistant bacteria in hematology patients has become a global concern[6]. Carbapenem de-escalation strategy for hematology patients would be useful for controlling antimicrobial resistance[7, 8]. Gudiol et al. compared the efficacy of BL/BLIs to carbapenems in two cohorts of hematological neutropenic patients with extended-spectrum- $\beta$-lactamase (ESBL) bloodstream infection (BSI) and found similar results in 30-day case fatality rates and other secondary outcomes, the authors concluded that BL/BLIs might be carbapenem-sparing alternatives for the treatment of BSI by ESBL-producing bacteria[9].

Although previous systematic reviews compared the effectiveness of piperacillin/tazobactam with carbapenem, conflicting results related to mortality were found[10,11]. No meta-analysis has compared BL/BLIs with carbapenems for treating febrile neutropenia. Therefore, we conducted a systematic review and meta analysis of randomized trials (RCTs) that compared BL/BLIs versus carbapenems for febrile neutropenia empiric therapy.

\section{Methods}

\section{Search strategy}

We performed a systematic review in accordance with the Preferred Reported Items for Systematic Reviews and Meta-analysis (PRISMA)[12]. A comprehensive search of the PubMed, Embase, Cochrane Library, Web of Science and Google scholar and ClinicalTrials. Additionally, a manual search of the retrieved articles, related review articles, and meta-analyses was conducted to identify other relevant articles. The search covered the time from each database's inception to 1 April 2020. We used the following key terms and their combination without language restrictions: "clavulanic", "sulbactam", "tazobactam", "avibactam", "beta-Lactamase Inhibitors", “imipenem”, “meropenem”, "biapenem”, "ertapenem”, "doripenem”, "panipenem”, "carbapenems",

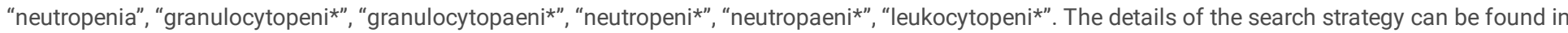
the Supplementary S1.

\section{Inclusion and exclusion criteria}

The definitions of febrile neutropenia can vary but should not deviate too much from guidelines: the cutoff neutrophil counts per liter were either 500 or 1000 , and the definitions of fever were a single oral temperature of $>38.3^{\circ} \mathrm{C}\left(101^{\circ} \mathrm{F}\right)$ or a temperature of $>38.0^{\circ} \mathrm{C}\left(100.4^{\circ} \mathrm{F}\right)$ sustained for $>1$ hour $[2,3$, 13]. We included RCTs comparing any BL/BLI versus any carbapenem for febrile neutropenia patients undergoing chemotherapy for either solid tumours or haematological malignancies among adults and children. Febrile neutropenic patients were randomly assigned to receive either BLBLs or carbapenem 
group antibiotics, adding the same antibiotic/treatment for both arms was accepted. The primary outcome was treatment success without modification of the antibiotic regimen, the secondary outcomes were all-cause mortality, infection related mortality and adverse events (AEs).

\section{Study selection and data extraction}

After eliminating duplicates by EndNote X9 software and manual check. Two reviewers (HY MENG and JY ZHANG) independently reviewed the titles and abstracts of records retrieved from the search and selected all potentially relevant studies according to the pre-defined inclusion and exclusion criteria. A pilot search was conducted before the full screening of the literature to ensure that each reviewers understood the screening criteria and process.

Disagreements about selection of studies were resolved by consulting a third party (AL ZHANG). The process of study selection was documented using a PRISMA flow diagram[14].

Two reviewers (HY MENG and JY ZHANG) independently extracted the following data from included trials using a standardized extraction sheet: 1) basic information (year of publication, first author and affiliation, journal, funding, conflict of interest; 2) study details (study design, sample size, research population characteristics, interventions, outcomes). A pre-test was conducted before formal extraction to ensure that each researcher agreed with the extraction criteria and process. Disagreements were solved through discussion with a third party (AL ZHANG).

\section{Risk of bias assessment}

Two reviewers (AL ZHANG and J YANG) assessed the quality of the included studies independently. We used the Cochrane bias risk assessment tool (Risk of bias) to assess the randomized controlled trials[15], examining the generation of the allocation sequence, allocation concealment, blinding, assessment of incomplete outcome data, selective outcome reporting, other basis (e.g. early conclusion of the trial and extreme imbalance at baseline).

Data synthesis

For the dichotomous variables, the risk ratios (RRs) were calculated and reported with the $95 \% \mathrm{Cls}$. The heterogeneity of the studies was measured using the $R$ statistics and the $Q$ test (heterogeneity $\chi^{2}$ ). A Q test result of $P<0.1$ or $R>50 \%$ indicates heterogeneity, the random-effects model was applied. If heterogeneity was absent in a study, a fixed-effects model was used. The meta analysis was conducted using RevMan 5.3.

We conducted subgroup analyses for the primary outcome according to the following patient subgroups: 1) adults versus children; 2) types of BL/BLIs. We found an insufficient number of studies to allow review authors to undertake sensitivity analysis to determine the effect of including/excluding studies with high risk of bias (e.g. as a result of inadequate concealment of allocation).

We assessed potential risk of publication bias through visual analysis funnel plot symmetry and egger's test by STATA 13.

\section{Results}

We identified 2173 articles in the initial literature search (Figure S1). After removing duplicates, we screened the titles and abstracts of 1864 records. 42 articles were retrieved for full-text reviewing. Finally, nine RCTs invovled 1925 episodes of patients that compared BL/BLIs with carbapenems fulfilled the inclusion criteria for this study[16-24]. Three[17, 20,23] of the 9 studies were conducted in Turkey, two[16, 24] were conducted in USA; and one study was conducted in Spain[18], Germany[21], China[19] and Japan[22]. These studies were conducted between 1996 and 2017. Seven studies[16, 17, 20-24] focused on haematological malignancy and solid malignancy; one study[19] focused on haematological malignancy and one study[18] was not specified. Five studies[16, 19-21, 24] included only adults, two[17, 23] included only children, one study[22] included mainly children, and the other one[18] did not provide the patient age. Among the 9 trials, piperacillin/tazobactam was evaluated in 6 trials[18-23] and cefoperazone/sulbactam in evaluated in 3 trials[16, 17, 24]. Amikacin was added to the treatment groups in one study[20] and vancomycin was used in another study[16] (Table 1). 
Table 1

Characteristics of included studies

\begin{tabular}{|c|c|c|c|c|c|c|c|c|c|}
\hline \multirow[t]{2}{*}{ Study } & \multirow[t]{2}{*}{ Country } & \multicolumn{2}{|c|}{ Age(median, range) } & \multirow{2}{*}{$\begin{array}{l}\text { Episodes } \\
\text { of } \\
\text { patients }\end{array}$} & \multicolumn{2}{|l|}{ Dose regimen } & \multirow[t]{2}{*}{ Outcomes } & \multirow{2}{*}{$\begin{array}{l}\text { Timing of } \\
\text { evaluation } \\
\text { for } \\
\text { treatment } \\
\text { success } \\
\text { without } \\
\text { modification }\end{array}$} & \multirow{2}{*}{$\begin{array}{l}\text { Mortality } \\
\text { observation } \\
\text { duration }\end{array}$} \\
\hline & & Carbapenems & BL/BLIs & & Carbapenems & BL/BLIs & & & \\
\hline $\begin{array}{l}\text { Bodey et } \\
\text { al. } \\
1996[16]\end{array}$ & USA & $50(18-79)$ & $\begin{array}{l}52(17- \\
84)\end{array}$ & 369 & $\begin{array}{l}\mathrm{IPM}\left(500 \mathrm{mg} / \mathrm{m}^{2}\right. \\
\times 4)+\operatorname{VAN}(1 \mathrm{~g} \times \\
2)\end{array}$ & $\begin{array}{l}\text { CFS }(3 g \times 3)+ \\
\operatorname{VAN}(1 g \times 2)\end{array}$ & $\mathbb{Q}, \mathbb{Z}$ & $\begin{array}{l}\text { End of } \\
\text { treatment }\end{array}$ & NA \\
\hline $\begin{array}{l}\text { Winston } \\
\text { et al. } \\
\text { 1998[24] }\end{array}$ & USA & $39(16-81)$ & $\begin{array}{l}47(16- \\
76)\end{array}$ & 203 & $\operatorname{IPM}(0.5 g \times 4)$ & $\mathrm{CFS}(6 \mathrm{~g} \times 2)$ & 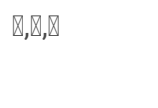 & $\begin{array}{l}\text { End of } \\
\text { treatment }\end{array}$ & NA \\
\hline $\begin{array}{l}\text { Figuera } \\
\text { et al. } \\
2001[18]\end{array}$ & Spain & NA & NA & 137 & $\operatorname{IPM}(0.5 \mathrm{~g} \times 4)$ & $\mathrm{TZP}(4.5 \mathrm{~g} \times 4)$ & $\bigotimes, \bigotimes, \bigotimes, \bigotimes$ & $\begin{array}{l}72 \mathrm{~h} \text { after } \\
\text { treatment }\end{array}$ & NA \\
\hline $\begin{array}{l}\text { Reich et } \\
\text { al. } \\
\text { 2005[21] }\end{array}$ & Germany & $44(18-70)$ & $\begin{array}{l}44(20- \\
63)\end{array}$ & 232 & $\operatorname{MEM}(1 \mathrm{~g} \times 3)$ & $\operatorname{TZP}(4.5 \mathrm{~g} \times 3)$ & 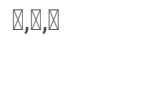 & $\begin{array}{l}72 \mathrm{~h} \text { after } \\
\text { treatment }\end{array}$ & $\begin{array}{l}7 \mathrm{~d} \text { after } \\
\text { treatment }\end{array}$ \\
\hline \multirow{2}{*}{$\begin{array}{l}\text { Oztoprak } \\
\text { et al. } \\
2010[20]\end{array}$} & \multirow[t]{2}{*}{ Turkey } & \multirow{2}{*}{\multicolumn{2}{|c|}{$52.79(17-83)$}} & 120 & $\begin{array}{l}\operatorname{MEM}(1 \mathrm{~g} \times 3)+ \\
\operatorname{AMK}(1 \mathrm{~g} \times 1)\end{array}$ & $\begin{array}{l}\text { TZP }(4.5 \mathrm{~g} \times 4)+ \\
\text { AMK }(1 \mathrm{~g} \times 1)\end{array}$ & 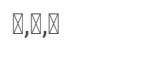 & $\begin{array}{l}\text { End of } \\
\text { treatment }\end{array}$ & $\begin{array}{l}\text { End of } \\
\text { treatment }\end{array}$ \\
\hline & & & & & $\begin{array}{l}\operatorname{IPM}(0.5 \mathrm{~g} \times 4)+ \\
\mathrm{AMK}(1 \mathrm{~g} \times 1)\end{array}$ & & & & \\
\hline $\begin{array}{l}\text { Vural et } \\
\text { al. } \\
2010[23]\end{array}$ & Turkey & $4(2-13)$ & $\begin{array}{l}5(2- \\
14)\end{array}$ & 99 & $\begin{array}{l}\text { IPM }(15 \mathrm{mg} / \mathrm{kg} \times \\
\text { 4) }\end{array}$ & $\begin{array}{l}\mathrm{TZP}(90 \mathrm{mg} / \mathrm{kg} \times \\
\text { 4) }\end{array}$ & 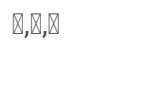 & $\begin{array}{l}\text { End of } \\
\text { treatment }\end{array}$ & $\begin{array}{l}\text { During } \\
\text { neutropenia }\end{array}$ \\
\hline \multirow[t]{2}{*}{$\begin{array}{l}\text { Demir et } \\
\text { al. } \\
2011[17]\end{array}$} & \multirow[t]{2}{*}{ Turkey } & \multirow[t]{2}{*}{$\begin{array}{l}7.5(0.58- \\
17.4)\end{array}$} & \multirow[t]{2}{*}{$\begin{array}{l}5.7(0.5- \\
17.16)\end{array}$} & \multirow[t]{2}{*}{208} & $\begin{array}{l}\text { IPM }(20 \mathrm{mg} / \mathrm{kg} \times \\
3)\end{array}$ & \multirow[t]{2}{*}{$\begin{array}{l}\mathrm{CFS}(60 \mathrm{mg} / \mathrm{kg} \times \\
\text { 3) }\end{array}$} & \multirow[t]{2}{*}{ 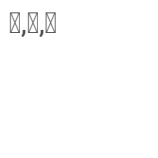 } & \multirow[t]{2}{*}{$\begin{array}{l}72 \mathrm{~h} \text { after } \\
\text { treatment }\end{array}$} & \multirow[t]{2}{*}{$\begin{array}{l}\text { During } \\
\text { treatment }\end{array}$} \\
\hline & & & & & $\begin{array}{l}\operatorname{MEM}(20 \mathrm{mg} / \mathrm{kg} \\
\times 3)\end{array}$ & & & & \\
\hline $\begin{array}{l}\text { Jing et } \\
\text { al. } \\
2016[19]\end{array}$ & China & $40(25-50)$ & $\begin{array}{l}41(25- \\
48)\end{array}$ & 123 & $\operatorname{IPM}(0.5 g \times 4)$ & $\mathrm{TZP}(4.5 \mathrm{~g} \times 4)$ & 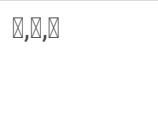 & $\begin{array}{l}\text { End of } \\
\text { treatment }\end{array}$ & $\begin{array}{l}\text { During } \\
\text { treatment }\end{array}$ \\
\hline $\begin{array}{l}\text { Sano et } \\
\text { al. } \\
2017[22]\end{array}$ & Japan & $10(0-25)$ & $\begin{array}{l}9(0- \\
25)\end{array}$ & 434 & $\begin{array}{l}\mathrm{MEM}(40 \mathrm{mg} / \mathrm{kg} \\
\times 3)\end{array}$ & $\begin{array}{l}\mathrm{TZP}(112.5 \mathrm{mg} / \mathrm{kg} \\
\times 3)\end{array}$ & 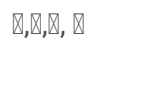 & $\begin{array}{l}120 \mathrm{~h} \text { after } \\
\text { treatment }\end{array}$ & NA \\
\hline \multicolumn{10}{|c|}{ IPM: imipenem/cilastatin, VAN: vancomycin, MEM: meropenem, CFS: cefoperazone/sulbactam, TZP: piperacillin/tazobactam, AMK: amikacin. } \\
\hline \multicolumn{10}{|c|}{ h: hour, d: day, NA: not available. } \\
\hline
\end{tabular}

More than half of the studies were assigned unclear risk of bias related to random sequencing, allocation concealment and blinding. One trial was judged as high risk by by lack of blinding. High risk of bias in incomplete outcome data were assigned because of the lack of data related to mortality and major outcomes. Three trials funded by pharmaceutical company were assigned high risk in other bias. (Fig. 1).

\section{Treatment success without modification}

Treatment success without modification was evaluated in 9 studies including 1925 episodes, with no difference between carbapenems and BL/BLIs in empiric treatment of febrile neutropenia (RR 1.04, 95\% Cl 0.93-1.15) (Fig. 2).

In a subgroup analysis including studies only for adults, carbapenems had a similar treatment success rate with $\mathrm{BL} / \mathrm{BLIs}$ (RR $1.04,95 \% \mathrm{Cl} 0.90-1.20$ ). In a subgroup analysis including studies only for children, no significant difference between carbapenems and BL/BLIs in treatment success rate (RR 0.99 , 95\% Cl 0.86-1.14) (Figure S2).

In a subgroup analysis by BL/BLIs, the pooled analysis of 6 studies showed carbapenems had a treatment success rate similar with piperacillin/tazobactam (RR 1.07, 95\% Cl 0.92-1.23), and cefoperazone/sulbactam (RR 0.97, 95\% Cl 0.90-1.04) (Figure S3)..

In the sensitivity analysis after studies were randomly excluded, similar RRs were observed $P=43 \%$ ). After excluding a study that only focused on haematological malignancy, heterogeneity $(R)$ between studies was less than $50 \%$.

The funnel plot for treatment success without modification was approximately symmetrical (Fig. 3). Egger's test was conducted to assess publication bias and no evidence of asymmetry was observed in treatment success without modification $(P=0.222)$.

Page $4 / 12$ 


\section{All-cause mortality}

All-cause mortality was reported in 7 studies, including 1457 episodes. No significant difference between carbapenems and BL/BLIs in mortality was observed (RR 1.15, 95\% Cl 0.64-2.06) (Fig. 4).

\section{Infection-related mortality}

Only two studies reported on the infection related mortality, including 637 episodes. A difference in favour of carbapenems was observed, but this difference was not statistically significant (RR $0.45,95 \%$ Cl 0.07-3.05) (Fig. 5).

\section{Adverse events}

Risk of nausea/vomiting was higher in the carbapenems arm compared with $\mathrm{BL} / \mathrm{BLIs}$ (RR $2.83,95 \% \mathrm{Cl} 1.35-5.92, P=0.006)$. Inversely, $\mathrm{BL} / \mathrm{BLIs}$ were associated with a significant increase in the risk of diarrhea relative to carbapenems (RR $0.47,95 \% \mathrm{Cl} 0.27-0.80, P=0.006)$. In addition, no significant difference was observed for rash ( $\mathrm{RR} 0.87,95 \% \mathrm{Cl} 0.39-1.92$ ), hepatotoxicity (RR 1.16, 95\% $\mathrm{Cl} 0.31-4.40$ ), and seizure (RR 4.05, 95\% Cl 0.68-24.31) (Fig. 6).

\section{Discussion}

To the best of our knowledge, this is the first study to compare BL/BLIs and carbapenems in empiric treatment of febrile neutropenia. No significantly difference was found between BL/BLIs and carbapenems in treatment success without modification. Similar results were observed in pooled analyses both adults and children in subgroup analysis. Treatment success rate of our findings are consistent with the network meta-analysis published by Horita et al. in 2017[11] which combined direct and indirect estimates. Another meta-analysis for cefoperazone/sulbactam in empiric therapy for febrile neutropenia by Lan et al. reported that cefoperazone/sulbactam had a treatment success rate similar to piperacillin/tazobactam and carbapenems[25]. Our study also revealed both piperacillin/tazobactam and cefoperazone/sulbactam had a similar success rate compared with carbapenems in subgroup analysis.

In terms of mortality, We found no differences between BL/BLIs and carbapenems in all cause mortality or infection related mortality. A meta-analysis for initial empirical treatment of febrile neutropenia by Paul et a/ reported that mortality was significantly lower with piperacillin/tazobactam compared with carbapenems (RR 0.46, 95\% $\mathrm{Cl} 0.22-0.95)$ [10]. Lan et al. reported that cefoperazone/sulbactam was not significantly different with other comparators in mortality through pooled analysis (OR $0.96,95 \% \mathrm{Cl} 0.58-1.58)$ [25]. Recently a single-center retrospective cohort study conducted by Benanti et al. showed empiric treatment with cefepime or piperacillin-tazobactam was not associated with increased 14-day mortality in neutropenic patients with hematologic malignancy and ESBL-producing E. coli bacteremia relative to that with empiric treatment with a carbapenem[26]. These findings favor the use of BL/BLIs in empiric treatment of febrile neutropenia.

Adverse events were slightly more common with carbapenems, but there was no statistical difference. Our study shows that gastrointestinal events are the most common adverse effects, nausea/vomiting were significantly more common with carbapenems. According to a previous systematic review included 21 trials by Shiber et al., diarrhea was significantly more common with BL/BLIs (RR 1.46, 95\% Cl 1.25-1.70)[27], which was consistent with our result from pooled analysis. In addition, higher rates of Clostridium difficile associated diarrhea were reported with carbapenems compared with BL/BLIs by Shiber et al.. This finding could not be supported by our review owing to limited reporting on Clostridium difficile in the included trials.

There are serveral limitations for this review. First, definitions of febrile neutropenia and timing of evaluation for treatment success were inconsistent across studies. Second, allocation concealment and blinding were unclear in most trials. Third, the number of people included in our study were low, a large scale RCT comparing a BL/BLI with a carbapenem should be conducted to confirm our findings.

\section{Conlusions}

We conducted a systematic review and meta-analysis invovled 9 RCTs to compare BL/BLIs with carbapenems for febrile neutropenia empiric therapy. Our study shows no advantage of carbapenems over BL/BLs in terms of treatment success rate and mortality, with more adverse events likely to occur supporting the use of BL/BLIs for empiric febrile neutropenia treatment. Well-designed RCTs are needed in order to support the beneficial effects of BL/BLs for febrile neutropenia empiric therapy in the future.

\section{Declarations}

\section{Funding:}

This study was carried out as part of our routine work.

\section{Availability of data and materials:}

All data generated or analysed during this study are included in this published article. 


\section{Ethics approval and consent to participate:}

Not applicable.

\section{Consent for publication:}

Not applicable.

\section{Conflict of interests:}

None of the authors have any conflicts of interest.

\section{Authors' contributions:}

Haiyang MENG conceived and designed the study, drafted of the manuscript. Jingyi ZHANG contributed in comprehensive research. Ailing ZHANG

Jingli LU designed the figures. Yanfang Ma and Qi ZHOU contributed in manuscript editing. Jian KANG and Xiaojian ZHANG revised the manuscript and approved the final version to be published. The author(s) read and approved the final manuscript.

\section{References}

1. Marti FM, et al. Management of febrile neutropenia: ESMO clinical recommendations. Ann Oncol. 2009;20(Suppl 4):166-9.

2. Baden LR, et al. Prevention and Treatment of Cancer-Related Infections, Version 2.2016, NCCN Clinical Practice Guidelines in Oncology. J Natl Compr Canc Netw. 2016;14(7):882-913.

3. Freifeld AG, et al. Clinical practice guideline for the use of antimicrobial agents in neutropenic patients with cancer: 2010 update by the infectious diseases society of america. Clin Infect Dis. 2011;52(4):e56-93.

4. Kulkarni AP, et al. Indian Antimicrobial Prescription Guidelines in Critically III Immunocompromised Patients. Indian J Crit Care Med. 2019;23(Suppl 1):S64-96.

5. Criscuolo M, Trecarichi EM. Ceftazidime/avibactam and ceftolozane/tazobactam for multidrug-resistant gram negatives in patients with hematological malignancies: Current experiences. Antibiotics. 2020;9(2):58.

6. Tatarelli P, Mikulska M. Multidrug-resistant bacteria in hematology patients: emerging threats. Future Microbiol. 2016;11:767-80.

7. Lew KY, et al. Safety and clinical outcomes of carbapenem de-escalation as part of an antimicrobial stewardship programme in an ESBL-endemic setting. J Antimicrob Chemother. 2015;70(4):1219-25.

8. Chong Y, et al. Antibiotic rotation for febrile neutropenic patients with hematological malignancies: clinical significance of antibiotic heterogeneity. PLoS One. 2013;8(1):e54190.

9. Gudiol C, et al., Efficacy of beta-Lactam/beta-Lactamase Inhibitor Combinations for the Treatment of Bloodstream Infection Due to ExtendedSpectrum-beta-Lactamase-Producing Enterobacteriaceae in Hematological Patients with Neutropenia. Antimicrob Agents Chemother, 2017. 61(8)

10. Paul M, et al., Anti-pseudomonal beta-lactams for the initial, empirical, treatment of febrile neutropenia: comparison of beta-lactams. Cochrane Database Syst Rev, 2010(11): p. CD005197.

11. Horita N, et al. Comparison of antipseudomonal beta-lactams for febrile neutropenia empiric therapy: systematic review and network meta-analysis. Clin Microbiol Infect. 2017;23(10):723-9.

12. Liberati A, et al., The PRISMA statement for reporting systematic reviews and meta-analyses of studies that evaluate healthcare interventions: explanation and elaboration. Bmj-British Medical Journal, 2009. 339.

13. Flowers $\mathrm{CR}$, et al. Antimicrobial prophylaxis and outpatient management of fever and neutropenia in adults treated for malignancy: American Society of Clinical Oncology clinical practice guideline. J Clin Oncol. 2013;31(6):794-810.

14. Moher D, et al. Preferred reporting items for systematic reviews and meta-analyses: the PRISMA statement. BMJ. 2009;339:b2535.

15. Higgins JP, et al., Cochrane handbook for systematic reviews of interventions. 2019: John Wiley \& Sons.

16. Bodey G, et al. Imipenem or cefoperazone-sulbactam combined with vancomycin for therapy of presumed or proven infection in neutropenic cancer patients. European journal of clinical microbiology infectious diseases. 1996;15(8):625-34.

17. Demir HA, et al. Comparison of sulbactam-cefoperazone with carbapenems as empirical monotherapy for febrile neutropenic children with lymphoma and solid tumors. Pediatr Hematol Oncol. 2011;28(4):299-310.

18. Figuera An, et al. Comparative study of piperacillin/tazobactam versus imipenem/cilastatin in febrile neutropenia (1994-1996). Medicina clinica. 2001;116(16):610-1.

19. Jing Y, et al. Piperacillin-tazobactam vs. imipenem-cilastatin as empirical therapy in hematopoietic stem cell transplantation recipients with febrile neutropenia. Clin Transplant. 2016;30(3):263-9.

20. Oztoprak N, et al. Piperacillin-tazobactam versus carbapenem therapy with and without amikacin as empirical treatment of febrile neutropenia in cancer patients: Results of an open randomized trial at a University hospital. Jpn J Clin Oncol. 2010;40(8):761-7. 
21. Reich G, et al. Empirical antimicrobial monotherapy in patients after high-dose chemotherapy and autologous stem cell transplantation: $A$ randomised, multicentre trial. Br J Haematol. 2005;130(2):265-70.

22. Sano $\mathrm{H}$, et al., A prospective randomized trial comparing piperacillin/tazobactam with meropenem as empirical antibiotic treatment of febrile neutropenic children and adolescents with hematologic and malignant disorders. Pediatric Blood and Cancer, 2017. 64(6).

23. Vural S, et al. Imipenem-cilastatin versus piperacillin-tazobactam as monotherapy in febrile neutropenia. Pediatr Int. 2010;52(2):262-7.

24. Winston DJ, et al. Randomized comparison of sulbactam/cefoperazone with imipenem as empirical monotherapy for febrile granulocytopenic patients. Clin Infect Dis. 1998;26(3):576-83.

25. Lan SH, et al. Efficacy and safety of cefoperazone-sulbactam in empiric therapy for febrile neutropenia: A systemic review and meta-analysis. Medicine. 2020;99(8):e19321.

26. Benanti GE, et al., Carbapenem versus Cefepime or Piperacillin-Tazobactam for Empiric Treatment of Bacteremia Due to Extended-Spectrum-betaLactamase-Producing Escherichia coli in Patients with Hematologic Malignancy. Antimicrobial Agents and Chemotherapy, 2019. 63(2).

27. Shiber $S$, et al. beta-Lactam/beta-lactamase inhibitors versus carbapenems for the treatment of sepsis: systematic review and meta-analysis of randomized controlled trials. J Antimicrob Chemother. 2015;70(1):41-7.

\section{Figures}

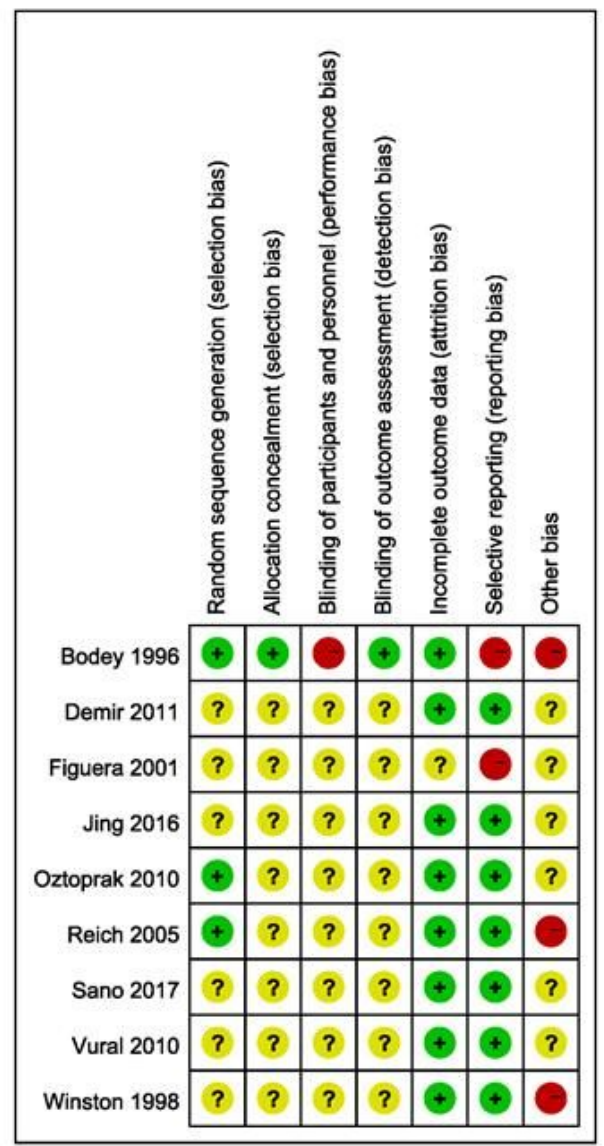

\section{Figure 1}

Risk of bias summary for each included study 


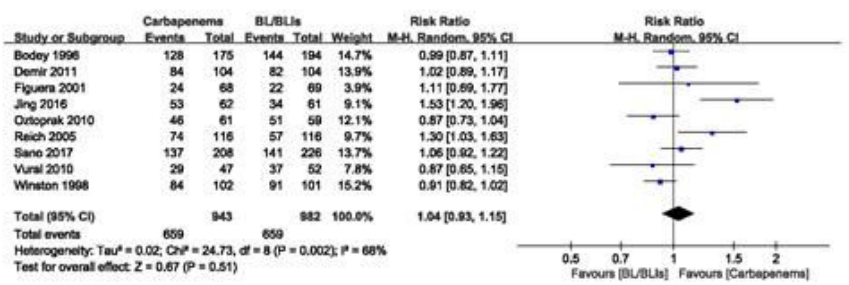

Figure 2

Forest plot for treatment success without modification 


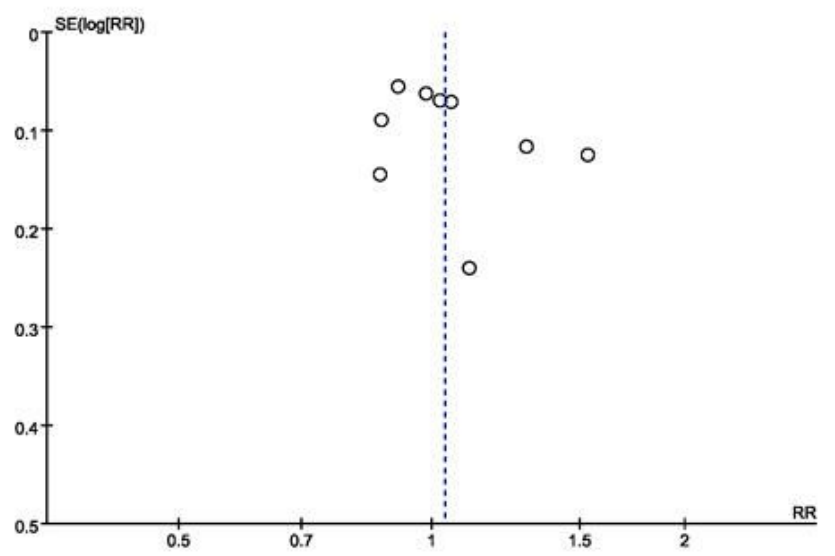

Figure 3

Funnel plot for treatment success without modification 


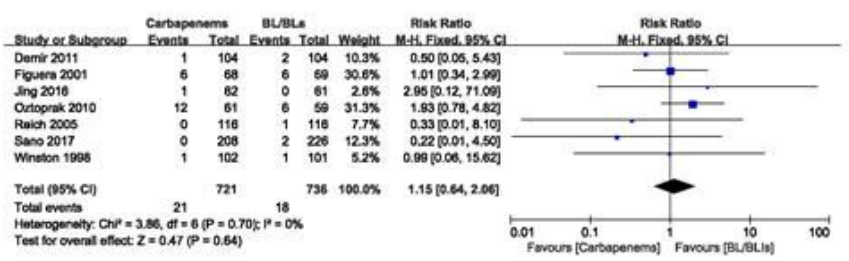

Figure 4

Forest plot for all-cause mortality 


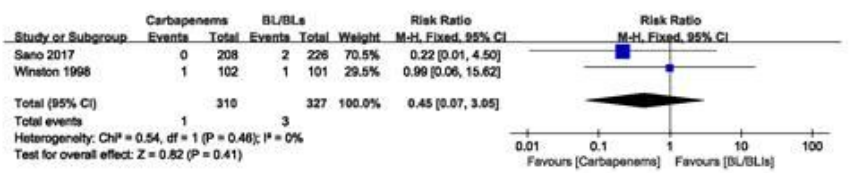

\section{Figure 5}

Forest plot for infection-related mortality 


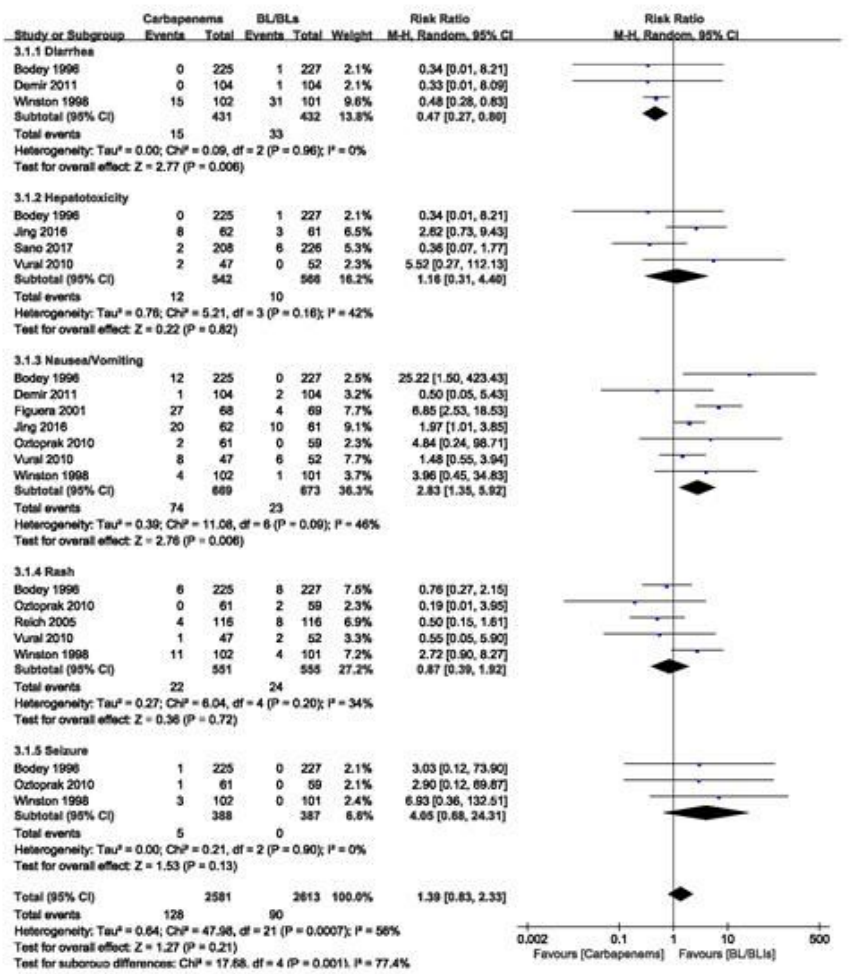

\section{Figure 6}

Forest plot for adverse events

\section{Supplementary Files}

This is a list of supplementary files associated with this preprint. Click to download.

- Supplementarydata.doc 